\title{
Study on breastfeeding practices among rural women in the field practice areas of a tertiary care teaching hospital
}

\author{
Noopur S. Nagar ${ }^{1}$, Ebbie Thomas ${ }^{2 *}$, Shashwat S. Nagar ${ }^{2}$, Naresh R. Godara ${ }^{2}$
}

\begin{abstract}
${ }^{1}$ Department of Obstetrics and Gynecology, ${ }^{2}$ Department of Community Medicine, Parul Institute of Medical Sciences and Research, Vadodara, Gujarat, India
\end{abstract}

Received: 17 December 2018

Accepted: 11 January 2019

\section{*Correspondence:}

Mr. Ebbie Thomas,

E-mail: ebbiethomas@gmail.com

Copyright: (c) the author(s), publisher and licensee Medip Academy. This is an open-access article distributed under the terms of the Creative Commons Attribution Non-Commercial License, which permits unrestricted non-commercial use, distribution, and reproduction in any medium, provided the original work is properly cited.

\begin{abstract}
Background: Breastfeeding is one of the most important determinants of child survival, birth spacing, and prevention of childhood infections. The beneficial effects of breastfeeding depend on breastfeeding initiation, its duration, and the age at which the breast-fed child is weaned. Data from NFHS-4 suggest that in India, in Gujarat where only 56\% of infants are exclusively breastfed and $50 \%$ of infants are initiated with breastfeeding within one hour of birth. This study was planned to identify the gaps in breastfeeding practices so that necessary interventions can be designed and thereby implemented. The objective is to study the breastfeeding practices of mothers having children below 2 years of age in the field practice areas of the medical college and to associate the findings of these practices with the sociodemographic characteristics of the population.

Methods: The study conducted was a community based cross-sectional one in the six villages of RHTC of PIMSR. The study was conducted by surveying a total of 204 mothers to study their breastfeeding practices which were categorized into 'good' and "not so good' practices. From this the total score was calculated and associated with socio-demographic variables.

Results: Majority of the mothers were in the age group 18-22 and educated up to 'primary' and most of them were from social class IV and V. Only $23 \%$ of the mothers had adequate knowledge of exclusive breastfeeding. About $70 \%$ practiced both early initiation of breastfeeding and feeding colostrum whereas nearly $80 \%$ practiced exclusive breastfeeding.

Conclusions: It is concluded from the study that even though the practice of breastfeeding was found quite good, the gaps in the knowledge and practice must be addressed through health education and support through peer and health groups. Documenting the success stories will go a long way for community education and behavioral change in communication at the community level for adequate breastfeeding practices.
\end{abstract}

Keywords: Breastfeeding, Colostrum, NFHS-4, Supplementary feeding

\section{INTRODUCTION}

Breastfeeding is one of the most important determinants of child survival, birth spacing, and prevention of childhood infections. The importance of breastfeeding has been emphasized in various studies. ${ }^{1,2}$ The importance of exclusive breastfeeding and the immunological and nutritional values of breast milk has been demonstrated. ${ }^{3,4}$ The initiation of breastfeeding and timely introduction of adequate, safe, and appropriate supplementary foods along with continued breastfeeding are crucial for the growth and development of infants and children. ${ }^{5}$ The beneficial effects of breastfeeding depend on breastfeeding initiation, its duration, and the age at 
which the breast-fed child is weaned. ${ }^{6}$ Breastfeeding practices vary among different regions and communities. In India, breastfeeding in rural areas appears to be shaped by the beliefs of a community, which are further influenced by social, cultural, and economic factors. ${ }^{1}$ Data from NFHS-4 suggest that in India, less than 55\% of children under 6 months of age are exclusively breastfed and about $40 \%$ are breastfed within one hour of birth. The results being very similar for Gujarat where only $56 \%$ of infants are exclusively breastfed and 50\% of infants are initiated with breastfeeding within one hour of birth. The field practice areas of the teaching hospital are catered by services of medical college and hence a high proportion of Institutional deliveries and tertiary level of $\mathrm{MCH}$ care is being routinely delivered. However, in spite of availability of services, there do exist challenges in providing comprehensive care to all residents of nearby villages. This study was therefore planned to identify the gaps in breastfeeding practices so that necessary interventions can be designed and thereby implemented.

The objectives of this study are to study the breastfeeding practices of mothers having children below two years of age in the field practice areas of the medical college and to associate the findings of these practices with the sociodemographic characteristics of the population.

\section{METHODS}

The study conducted was community based crosssectional in the 6 villages of the rural health training Centre of Parul Institute of Medical Sciences in Vadodara, Gujarat. The study was conducted by going house to house and surveying mothers having children less than 2 years of age. The study was conducted from September to November 2016. The study covered all the 204 mothers residing in the 6 villages who consented for the study. The data was collected by directly questioning the subjects after their verbal and written consent using a predesigned and pretested questionnaire. The 'good' practices were given a score of 1 and 'Not so Good' practices were given a score of 0 . From this, the total score was calculated by adding up all four individual scores, those having 2 or more variables with a score of good were categorized as having "good" practices whereas the remaining were categorized as having "not so good" practices. The breastfeeding practices among the subjects were assessed by categorizing them into good and not so good depending upon the merits of the practice of full ANC check-ups (at least 4), practice of exclusive breastfeeding, feeding colostrum, and early initiation of breastfeeding.

\section{Statistical analysis}

The final category of the participants was then associated with the various socio-demographic variables using chi squared test. The relevant statistics in the study were computed and analyzed using MS Excel 2007.

\section{RESULTS}

The study was carried out among a total of 204 mothers having children below 2 years of age residing in the field practice areas under the RHTC (Rural health training centre) of medical college.

Table 1: Socio-demographic features of the mothers.

\begin{tabular}{|c|c|c|c|}
\hline \multicolumn{2}{|c|}{$\begin{array}{l}\text { Socio- } \\
\text { demographic } \\
\text { features }\end{array}$} & Frequency & $\%$ \\
\hline \multirow{4}{*}{$\begin{array}{l}\text { Age (in } \\
\text { years) }\end{array}$} & $18-22$ & 90 & 44.1 \\
\hline & $23-27$ & 43 & 21.1 \\
\hline & $28-32$ & 68 & 33.3 \\
\hline & $33+$ & 3 & 1.5 \\
\hline \multirow{3}{*}{ Education } & Illiterate & 42 & 20.6 \\
\hline & Primary & 117 & 57.4 \\
\hline & Secondary & 45 & 22.1 \\
\hline \multirow{5}{*}{ Occupation } & Professional & 6 & 3.0 \\
\hline & Semi-professional & 10 & 5.1 \\
\hline & Skilled workers & 27 & 13.0 \\
\hline & Unskilled workers & 50 & 24.5 \\
\hline & $\begin{array}{l}\text { Unemployed } \\
\text { (Housewife) }\end{array}$ & 111 & 54.4 \\
\hline \multirow{5}{*}{$\begin{array}{l}\text { Social } \\
\text { class }\end{array}$} & Class I & 17 & 8.3 \\
\hline & Class II & 25 & 12.1 \\
\hline & Class III & 41 & 20.0 \\
\hline & Class IV & 66 & 32.3 \\
\hline & Class V & 55 & 27.0 \\
\hline \multicolumn{2}{|c|}{ Total (for each category above) } & 204 & $\begin{array}{l}100 . \\
0\end{array}$ \\
\hline
\end{tabular}

Out of the total surveyed population, majority of the mothers were in the age group 18-22 followed by those in the age group 28-32. This shows a tendency for early pregnancy in the surveyed population as majority of the subjects were aged less than 28 years. Most of the subjects were educated up to primary whereas nearly $20 \%$ of the subjects were illiterates. Most of the women were housewives (nearly $55 \%$ ) whereas those working as skilled or unskilled workers were nearly $40 \%$. The social class of the subjects was accessed on the basis of the modified Prasad's classification based on per capita income. It was seen that about $60 \%$ of the subjects belonged to the social class IV and V whereas only $20 \%$ belonged to class I and II (Table 1). As per the guidelines of RMNCH+A program, a minimum of 4 check-ups are required during the antenatal period. Figure 1 shows that nearly $60 \%$ had had those 4 check-ups done. $15 \%$ of the subjects have undergone only 3 antenatal check-ups whereas $22 \%$ underwent only 1 or 2 antenatal check-ups. (Figure1). When the subjects were asked regarding the essentials of breastfeeding like early initiation, exclusive breastfeeding up to 6 months, and supplementary feeding beyond 6 months; it was found that only $23 \%$ of the subjects had adequate knowledge regarding the same (Figure 2). 


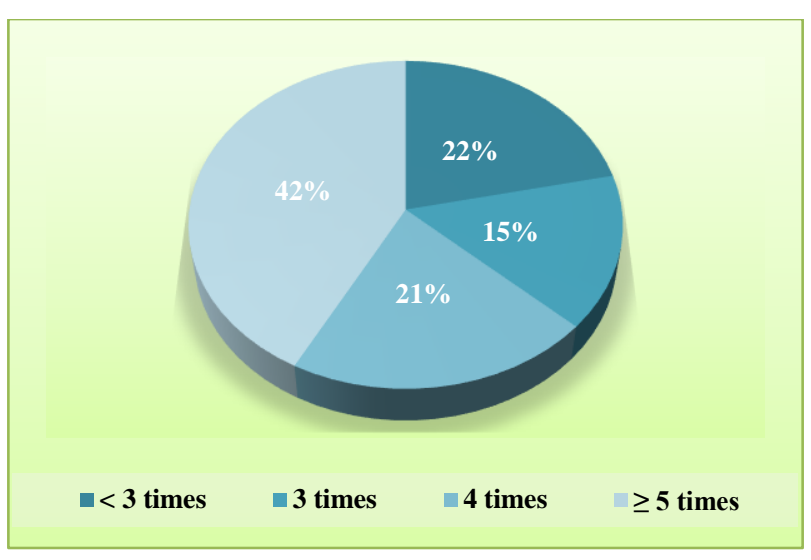

Figure 1: Frequency of prenatal check-ups.

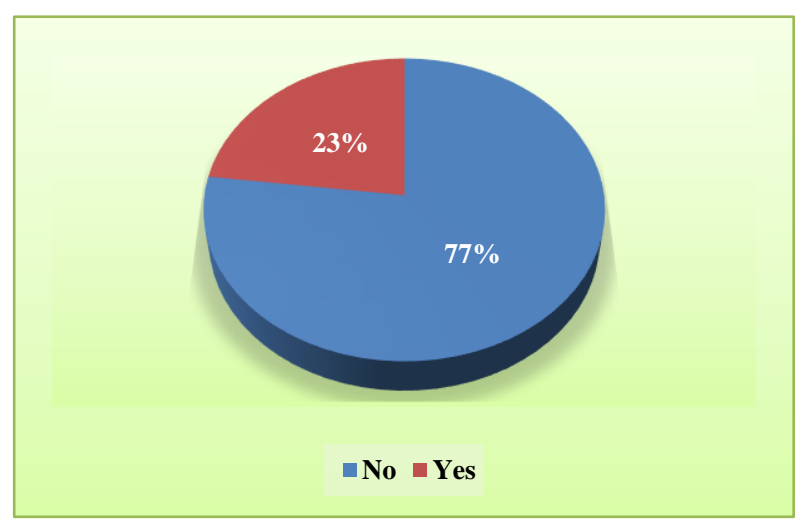

Figure 2: Knowledge of exclusive breastfeeding.
The breastfeeding practices among the study subjects were assessed including early initiation of breastfeeding (within 1 hour), feeding colostrum to the new-born baby and the practice of exclusive breastfeeding up to 6 months followed by supplementary feeding in addition.

Table 2: Breastfeeding practices among the study subjects ( $n=204)$.

\begin{tabular}{|c|c|c|c|}
\hline \multicolumn{2}{|c|}{ Breastfeeding practices } & \multirow{2}{*}{$\begin{array}{l}\text { Frequency } \\
134\end{array}$} & \multirow{2}{*}{$\begin{array}{l}\text { Percentage } \\
65.7\end{array}$} \\
\hline \multirow{4}{*}{$\begin{array}{l}\text { Initiation } \\
\text { of } \mathrm{BF}\end{array}$} & $\begin{array}{l}\text { Within } 1 \\
\text { hour }\end{array}$ & & \\
\hline & In 1-6 hour & 48 & 23.5 \\
\hline & In 6-24 hour & 12 & 5.9 \\
\hline & $\begin{array}{l}\text { More than } \\
24 \text { hours }\end{array}$ & 10 & 4.9 \\
\hline \multirow{2}{*}{$\begin{array}{l}\text { Feeding } \\
\text { Colostrum }\end{array}$} & Colostrum & 142 & 69.6 \\
\hline & Pre-lactation & 62 & 30.4 \\
\hline \multirow{4}{*}{$\begin{array}{l}\text { Exclusive } \\
\text { BF }\end{array}$} & $\begin{array}{l}<6 \text { months } \\
\text { and not } \\
\text { weaning }\end{array}$ & 55 & 27.0 \\
\hline & $\begin{array}{l}<6 \text { months } \\
\text { and weaning }\end{array}$ & 23 & 11.3 \\
\hline & $\begin{array}{l}>6 \text { months } \\
\text { and not } \\
\text { weaning }\end{array}$ & 11 & 5.4 \\
\hline & $\begin{array}{l}>6 \text { months } \\
\text { and weaning }\end{array}$ & 115 & 56.4 \\
\hline \multicolumn{2}{|c|}{$\begin{array}{l}\text { Total } \\
\text { (for each category above) }\end{array}$} & 204 & 100.0 \\
\hline
\end{tabular}

Table 3: Association of breastfeeding practices among the study subjects with their socio-demographic variables.

\begin{tabular}{|c|c|c|c|c|c|c|}
\hline \multirow{2}{*}{$\begin{array}{l}\text { Socio-demographic } \\
\text { features }\end{array}$} & \multirow{2}{*}{ Categories } & \multicolumn{3}{|c|}{ Breastfeeding practices } & \multirow{2}{*}{ Chi-square } & \multirow{2}{*}{ P-value } \\
\hline & & Good & Not so good & Total & & \\
\hline \multirow{4}{*}{ Age } & $18-22$ & 74 & 16 & 90 & \multirow{4}{*}{3.94} & \multirow{4}{*}{0.27} \\
\hline & $23-27$ & 38 & 5 & 43 & & \\
\hline & $28-32$ & 51 & 17 & 68 & & \\
\hline & $33+$ & 3 & 0 & 3 & & \\
\hline \multirow{3}{*}{ Education } & Illiterate & 22 & 20 & 42 & \multirow{3}{*}{32.57} & \multirow{3}{*}{$<0.01$} \\
\hline & Primary & 100 & 17 & 117 & & \\
\hline & Secondary & 44 & 1 & 45 & & \\
\hline \multirow{5}{*}{ Occupation } & Professional & 4 & 2 & 6 & \multirow{5}{*}{2.33} & \multirow{5}{*}{0.67} \\
\hline & Semi-professional & 7 & 3 & 10 & & \\
\hline & Skilled workers & 21 & 6 & 27 & & \\
\hline & Unskilled workers & 42 & 8 & 50 & & \\
\hline & Unemployed (housewife) & 92 & 19 & 111 & & \\
\hline \multirow{5}{*}{ Social class } & Class I & 9 & 8 & 17 & \multirow{5}{*}{16.64} & \multirow{5}{*}{$<0.01$} \\
\hline & Class II & 20 & 5 & 25 & & \\
\hline & Class III & 32 & 9 & 41 & & \\
\hline & Class IV & 62 & 4 & 66 & & \\
\hline & Class V & 43 & 12 & 55 & & \\
\hline \multicolumn{2}{|c|}{ Total (for each category) } & 166 & 38 & 204 & & \\
\hline
\end{tabular}


It was seen that nearly $70 \%$ practiced both early initiation of breastfeeding and feeding colostrum whereas nearly $80 \%$ practiced exclusive breastfeeding (Table 2). After the categorisation, the breastfeeding practices were associated with the socio-demographic features of the subjects.

There was a statistically significant association of Education and Social class with the breastfeeding practices whereas the association of age and occupation was insignificant. (Table 3).

\section{DISCUSSION}

The study was conducted in the 6 villages of the RHTC Catchment area on 204 mothers having children below 2years of age to analyses their breastfeeding practices. The study showed that majority of the subjects were aged less than 21 years showing a tendency of early marriage and child bearing as seen in most of the rural areas of the state. It also showed that nearly $20 \%$ of the mothers were illiterate which can by itself have a significant impact on their breastfeeding practices. Most of the study subjects were from Social Class $\mathrm{V}$ and either unemployed (housewife) or working as laborer's which is the predominant occupation of people living in these villages.

Having two medical colleges as tertiary care centers in the near vicinity providing CEmOC services, it is expected that the health seeking behavior of the catchment population including the villages in the present study would be better than other peripheral areas which are far off from health centers. It was seen that nearly $60 \%$ of the mothers had had four or more antenatal check-ups. The data is comparable to NFHS-4 findings which showed nearly $70 \%$ had four or more ANC visits. ${ }^{7}$ Identifying maternal factors early during the ANC period helps and goes a long way in preventing under-five malnutrition. Counselling sessions during the ANC period play a pivotal role in improving the breastfeeding practices which by itself is one of the most important factors for improving child survival.

It came across in the study that majority of the mothers did not have an adequate knowledge regarding breastfeeding. This was quite different from a study conducted in hospital settings in urban Vadodara by Bhatt $\mathrm{S}$ et al, which suggested that $84 \%$ of the mothers were aware of exclusive breastfeeding. This difference could have been due to the differences in the perceptions of rural and urban population and also due to the study being conducted in community settings. ${ }^{8}$ Other studies conducted in the urban slums and rural areas also found about $72 \%$ of mothers aware of exclusive breastfeeding and its benefits. ${ }^{9,10}$

The present study showed that $66 \%$ of the mothers gave exclusive breastfeeding to the new-borns which is a little higher than the average found in NFHS-4. This difference could have been because of a higher institutional delivery rate because of the nearby medical colleges. Bhatt et al, found that nearly $30 \%$ of the mothers practiced exclusive breastfeeding which is quite low considering the fact that the study was conducted in hospital settings. The present study showed that about $70 \%$ of mothers gave colostrum to their babies. These findings are similar to Rani $\mathrm{S}$ et al, who carried out her study on breastfeeding practices in urban slums of Visakhapatnam. ${ }^{11}$ It was also seen in the study that nearly $83 \%$ of the mothers gave exclusive breastfeeding and started supplementary feeding on time.

About $11 \%$ of the mothers started supplementary feeding before 6 mothers and about 5\% started it late. This shows that the appropriate support for breastfeeding even though has been provided still there are about $20 \%$ who need to be first educated and then provided support with for early initiation, exclusive breastfeeding, and the appropriate age for supplementary feeding. This would go a long way in prevention of malnutrition as the age at weaning has often been found directly associated with malnutrition. The association of the socio-demographic features with the breastfeeding practices showed that education and social class were found to be statistically significantly associated with breastfeeding practices. Even though most of the social factors determine the health practices and health seeking behavior the same can be influenced by behavioral change communication.

\section{CONCLUSION}

It can be concluded from the study that even though the mothers practiced exclusive breastfeeding to a high extend and were aware of the benefits of exclusive breastfeeding, there still exists some gap in the practice of adequate breastfeeding practices which is critical towards the growth and development of the child. An increase in the institutional delivery rate and community-based projects focusing on the awareness and support of breastfeeding can play a pivotal role in ensuring the adequacy of these practices.

\section{Recommendations}

The above study has pointed out that there does exist some gap in the knowledge levels of the community and the practices for exclusive breastfeeding. These can be improved upon by persistent health education sessions in the community and also by carrying out home visits to provide support to postnatal mothers. Colostrum being an integral part of the induction of a child's immunity system should necessarily be given and the mothers must be educated for the same. ASHAs carrying out house to house visits during the postnatal period must ensure that exclusive breastfeeding practiced, and the supplementary feeding is started only at the right age. Self-help groups and peers can play an important role in providing a link between community and the health system. They should be not only developed but also promoted in each village. Documenting the success stories will go a long way for community education and behavioral change in 
communication at the community level for adequate breastfeeding practices.

\section{ACKNOWLEDGMENTS}

Authors would like to acknowledge the students, Kajal Gajjar, Teryson Tailor, Rupal Rathod, Sanjay Patel, and Anand Jee for their contribution in the research project.

Funding: No funding sources

Conflict of interest: None declared

Ethical approval: The study was approved by the Institutional Ethics Committee

\section{REFERENCES}

1. Iskandar MB, Costello C, Nasution Y. Initiation and Duration of Breast feeding in Indonesia. Asia Pac Popul J. 1990;5:89-112.

2. Bautista LE. Factors associated with initiation of breast feeding in the domician Republic. Rev Panam Salud Publica. 1997;1:200-7.

3. Arifeen S, Black RE, Antelman G, Baqui A, Caulfield L, Becker S. Exclusive breast-feeding reduces acute respiratory infection and diarrhea deaths among infants in Dhaka slums. Pediat. 2001;108:E67.

4. Dewey KG, Cohen RJ, Brown KH, Rivera LL. Effects of exclusive breast-feeding for four versus six months on maternal nutritional status and infant motor development: Results of two randomized trials in Honduras. J Nutr. 2001;131:262-7.
5. Jha R, Kumar S. Breastfeeding Practices in a rural community of Moradabad, Uttar Pradesh. Indian Med J. 2010;105(5):169-71.

6. Victora CG, Smith PG, Vaughan JP, Nobre LC, Lombardi C, Teixeira AM, et al. Evidence for protection against infant deaths from infectious diseases in Brazil Lancet. 1987;2:319-22.

7. National Family Health Survey-4. Ministry of Health and Family Welfare. 2015-16.

8. Bhatt S, Parikh P, Kantharia N, Dahat A, Parmar R. Knowledge, attitude and practice of post natal mothers for early initiation of breastfeeding in the obstetric wards of a tertiary care hospital of Vadodara city. National J Commun Med. 2012;3(2):305-9.

9. Kulkarni RN, Anjenaya S, Gujar R. Breast feeding practices in an urban community of kalamboli, Navi Mumbai. Indian J Community Med. 2004;29(4):2367.

10. Bandyopadhyay SK, Chaudhary N. Mukopadhyaya $\mathrm{BB}$, Breast Feeding Practices in rural areas of West Bengal. Indian J Public Health. 2000; 44:137-8.

11. Rani S, Rao S. Breastfeeding Practices among Relli mothers in Urban Slums of Visakhapatanam. Indian J Maternal Child Health. 210;12(3):1-8.

Cite this article as: Nagar NS, Thomas E, Nagar SS, Godara NR. Study on breastfeeding practices among rural women in the field practice areas of a tertiary care teaching hospital. Int $\mathbf{J}$ Reprod Contracept Obstet Gynecol 2019;8:462-6. 